\title{
Evaluation of genotoxicity through micronuclei test in workers of car and battery repair garages
}

\author{
M.G. Martino-Roth ${ }^{1}$, J. Viégas ${ }^{1}$, M. Amaral $^{2}$, L. Oliveira ${ }^{2}$, F.L.S. Ferreira ${ }^{1}$ and B. Erdtmann ${ }^{3}$ \\ ${ }^{1}$ Departamento de Zoologia e Genética, Instituto de Biologia, Universidade Federal de Pelotas, \\ Pelotas, RS, Brazil. \\ ${ }^{2}$ Departamento de Morfologia, Instituto de Biologia, Universidade Federal de Pelotas, Pelotas, RS, Brazil. \\ ${ }^{3}$ Departamento de Genética, Universidade Federal do Rio Grande do Sul, Porto Alegre, RS, Brazil.
}

\begin{abstract}
In this study, the micronuclei test (MNT) was applied in exfoliated cells of buccal mucosa, in order to evaluate the genotoxic risk associated with occupational exposure of mechanics, storage battery renovation workers, and car painters. For each individual, 3000 exfoliated buccal cells were analyzed. There was a significantly higher frequency of micronucleated cells (MNC) in the exposed workers than in controls. Smoking and drinking habits, age, and working time did not represent significant factors in terms of increasing the production of micronuclei (MN), when the control and the exposed groups were compared. These results allowed to conclude that the studied individuals belong to a risk group and should periodically undergo biological monitoring and proper care.
\end{abstract}

Key words: micronucleus test, occupational exposure.

Received: March 13, 2002; accepted: August 13, 2002.

\section{Introduction}

Health suffers the influence of inherited, nutritional, and environmental factors. Populations of industrial areas are intensely exposed to chemical substances that can cause mutations, cancer, and congenital defects (Hirvonen, 1995). Occupational agents can induce several types of cancer, such as urinary tract, skin, larynx, and pancreas cancers, and leukemias (Santos-Mello and Cavalcante, 1992). Since the exposure to hazardous agents can be identified, actions to decrease their presence in the environment or to protect the population against them can minimize the consequences on people's health. One way to study the effects on an exposed population is to conduct monitoring studies, using pertinent biological parameters with a shortterm manifestation, such as cytogenetic analysis, by which damages to the DNA or to the chromosomes resulting from exposure can be identified. The obtained information can be used as an early warning about the potential risk of health problems developing in the long run (Au, 1991).

The use of the micronuclei test (MNT) to detect and quantify the genotoxic action of carcinogenics is well established in several systems, either in vitro or in vivo, its sensitivity being compared to the analysis of chromatid

Send correspondence to Maria da Graça Martino Roth. Rua Visconde de São Gabriel, 131, Bairro Areal, 96077-260 Pelotas, RS, Brazil. E-mail: gmartino@zaz.com.br. breaks and exchanges (Kliesch and Adler, 1980). This test presents great advantages over other techniques, not requiring cell culture nor metaphase preparations, it is applicable on interphase cells, is a good indicator of chromosome mutations (Majer et al., 2001), is not invasive and has a low cost (Titenko-Holland et al., 1994; Broschinski et al., 1998; Calvert et al., 1998; Keshava et al., 1998; Maluf and Erdtmann, 2000).

With the purpose of contributing to improve the quality of life of informal workers and workers in small and micro-businesses, we studied three different groups of subjects: a group of workers of a car repair garage, exposed to gas and petrol compounds; a group of car painters, exposed to lead (paint), solvents and benzene; and a group of storage battery renovation workers, exposed mainly to lead. Our objective was to evaluate by MNT the level of damage, and to establish the relationship of the micronucleus $(\mathrm{MN})$ frequency with non-occupational factors, such as the smoking and drinking habits, age, and time of working in this environment. All these workers frequently work in the same workshop, where they are exposed to more than one risk factor.

\section{Materials and Methods}

The study sample was composed of 60 workers of car and battery repair garages ( 20 general mechanics, 20 car 
painters, and 20 storage battery renovation workers); 80 workers who were not exposed to byproducts of petrol and lead were used as control group. All individuals were males, and answered a questionnaire about their occupational and non-occupational exposure, habits and diets, according to the protocol published by the International Commission for Protection against Environmental Mutagens and Carcinogens (Carrano, 1988).

Exfoliated cells of the buccal mucosa were obtained by scraping with a tongue depressor in the oral cavity. For each individual, two slides were prepared by smearing the cells onto pre-cleaned slides. The slides were then air-dried and fixed with methanol. The staining procedure was the Feulgen reaction for the identification of nuclear and $\mathrm{MN}$ DNA, followed by counterstain with Fast Green to delineate the cell cytoplasm.

The $\mathrm{MN}$ analysis was done in a light microscope, at a 100x magnification and a 10x eye-piece, using coded slides. 3000 cells from each individual were observed, and the results were expressed as frequencies of micronucleated cells (MN) in 3000 cells.

Only cells which were non-fragmented, non-accumulated, non-overlaid, and had an untouched nucleus were examined. Cells that were in a degeneration process, such as cariorexis or cariolysis, had a fragmented nucleus, or looked like a "broken egg" were registered aside, according to Tolbert et al. (1992). The criteria used to accept a formation as being a micronucleus were those recommended by Picker and Fox (1986) and by Titenko-Holland et al. (1998). Statistical analysis was performed by using twotailed Student's $t$ test, with a 0.05 probability or less.

\section{Results}

The main characteristics showing the profile of the tested and control subjects who took part in this study are presented in Table I. The studied individuals were classified according to their age, working time, and smoking and drinking habits.

Table II shows the data regarding the total numbers of cells with micronuclei (MNC) of both the workers and controls evaluated in this research. A significant difference $(p<0.001)$ was found between the exposed and the control groups regarding the average number of MNC. There was no significant difference between the three groups of exposed workers regarding the averages of $\mathrm{MNC}$, but there was a significant difference between each one of these groups and the control group $(\mathrm{p}<0.001)$.

The averages of MN per cell in the exposed workers were: $2 \mathrm{MN}-0.1 \pm 3.07$; $3 \mathrm{MN}-0.83 \pm 1.56$; and total number of MN-10.86 \pm 7.97 . In the non-exposed (control) group, they were: $2 \mathrm{MN}-0.09 \pm 0.28 ; 3 \mathrm{MN}-0.06 \pm 0.29$; and total number of MN-2.42 \pm 3.79 . There was a significant difference $(p<0.001)$ between the exposed and the control groups, both regarding the average of $3 \mathrm{MN}$ per cell and the total number of MN.

Concerning the smoking habit, the study showed that there was no significant difference between the average of MNC in smokers and non-smokers, either in the exposed workers and in the controls (Table III). Similar results were found in the analysis of the average number of MNC, as related to the drinking habit (Table IV).

Table V shows the MNC data of each of the three categories of exposed workers . The frequency analysis of $\mathrm{MNC}$ in each group with regard to the drinking habit was significant in the car painters' $(\mathrm{p}<0.05)$ and in the storage battery renovation workers' $(p<0.01)$ groups. No differences were detected in the mechanics and control groups.

Table II - Average numbers of micronucleated cells (in 3000 cells analyzed per individual) of the three groups of individuals exposed to byproducts of petrol and lead and controls.

\begin{tabular}{|c|c|c|c|c|c|}
\hline \multirow{2}{*}{$\begin{array}{l}\text { Sample } \\
\text { Individuals }\end{array}$} & \multirow[b]{2}{*}{ n. } & \multicolumn{4}{|c|}{ Micronucleated cells } \\
\hline & & Average & $\begin{array}{l}\text { Standard } \\
\text { deviation }\end{array}$ & $\begin{array}{c}\text { Minimum } \\
\text { number }\end{array}$ & $\begin{array}{c}\text { Maximum } \\
\text { number }\end{array}$ \\
\hline \multicolumn{6}{|l|}{ Exposed: } \\
\hline Battery & 20 & $8,55^{* * *}$ & 5,08 & 3 & 25 \\
\hline \multirow[t]{2}{*}{ Painters } & 20 & & 4,34 & 4 & 18 \\
\hline & & $8,85^{* * *}$ & & & \\
\hline \multirow[t]{2}{*}{ Mechanics } & 20 & & 3,47 & 3 & 16 \\
\hline & & $7,25 * * *$ & & & \\
\hline Total & 60 & $8,22 * * *$ & 4,34 & 3 & 25 \\
\hline \multicolumn{6}{|l|}{ Non-exposed: } \\
\hline Controls & 80 & 2,12 & 1,62 & 0 & 6 \\
\hline
\end{tabular}

***Significantly different from controls, $\mathrm{p}<0.001$, by Student's $t$ test (two-tailed).

Table I - Characterization of groups and subgroups of individuals, exposed and non-exposed to byproducts of petrol and lead, who took part in the study.

\begin{tabular}{|c|c|c|c|c|c|}
\hline Characteristics & Controls $\mathrm{n}=80$ & Exposed (total) $n=60$ & Battery $n=20$ & Painters $n=20$ & Mechanics $n=20$ \\
\hline Average age variation & $\begin{array}{c}33.37 \text { years } \\
23-50\end{array}$ & $\begin{array}{c}37.66 \text { years } \\
15-63\end{array}$ & $\begin{array}{c}36.05 \text { ys. } \\
20-56\end{array}$ & $\begin{array}{c}33.30 \text { years } \\
15-49\end{array}$ & $\begin{array}{c}43.65 \text { years } \\
23-63\end{array}$ \\
\hline Smokers & $22(27.5 \%)$ & $23(38.33 \%)$ & $10(50 \%)$ & $9(45 \%)$ & $04(20 \%)$ \\
\hline Non-smokers & $58(72.5 \%)$ & $37(61.67 \%)$ & $10(50 \%)$ & $11(55 \%)$ & $16(80 \%)$ \\
\hline With drinking habit & $65(81.25 \%)$ & $45(75 \%)$ & $18(90 \%)$ & $15(75 \%)$ & $12(60 \%)$ \\
\hline Without drinking habit & $15(18.75 \%)$ & $15(25 \%)$ & $02(10 \%)$ & $05(25 \%)$ & $08(40 \%)$ \\
\hline Average Period of work & 9.8 years & 10.11 years & $10.15 \mathrm{ys}$ & 7.25 years & 12. 95 years \\
\hline Variation & $1-27$ & $1-36$ & $1-36$ & $1-36$ & $3-30$ \\
\hline
\end{tabular}


Table III - Average numbers of micronucleated cells (in 3000 cells analyzed per individual) of the group of individuals exposed to byproducts of petrol and lead, and of controls, grouped by smoking habit.

\begin{tabular}{llcccc}
\hline Sample. & & \multicolumn{4}{c}{ Micronucleated cells } \\
\cline { 3 - 6 } Individuals & $\mathrm{n}$ & Average & $\begin{array}{c}\text { Standard } \\
\text { deviation }\end{array}$ & $\begin{array}{c}\text { Minimum } \\
\text { number }\end{array}$ & $\begin{array}{c}\text { Maximum } \\
\text { number }\end{array}$ \\
\hline Exposed: & & & & & \\
$\quad$ Smokers & 23 & 6,82 & 3,65 & 3 & 18 \\
$\quad$ Non-smokers & 37 & 9,08 & 4,54 & 3 & 25 \\
Controls: & & & & & \\
$\quad$ Smokers & 22 & 1,81 & 1,43 & 0 & 5 \\
$\quad$ Non-smokers & 58 & 2,36 & 1,67 & 0 & 6 \\
\hline
\end{tabular}

The individuals of the exposed group were evaluated for the interaction between smoking and drinking habits (Table VI). A significant difference was observed only between smokers/without a drinking habit and non-smokers/ with a drinking habit drinkers, at the $\mathrm{p}<0.01$ level.

The group under study was analyzed with regard to age within the following intervals: 15 to 30,31 to 40,41 to 50 , and 51 to 63 years. No differences were detected among the different age groups, either in the control and in the exposed individuals' group, regarding the increase of the MNC frequency. The three categories of exposed workers were evaluated separately, in order to assess the existence of any correlation between age and MN frequency, but no difference was found between their different age brackets.

The results obtained from the relation between the number of cells with $\mathrm{MN}$ in the exposed and control groups and the working time ( 1 to $5 ; 6$ to $15 ; 16$ to 25 ; and 26 to 36 years) did not show any increase in the frequency of $\mathrm{MN}$, when the three subgroups and the control group were considered separately.

\section{Discussion}

The three exposed subgroups (workers in general car mechanics, painting, and storage battery renovation) had an increased MNC frequency, as compared to controls $(\mathrm{p}<0.001)$, and a slight, non-significant difference was found between the exposed individuals. These findings prove that the substances to which they are exposed cause an increase in the number of MNC and are, therefore, genotoxic. This result is in conformity with the findings of Santos-Mello and Silva (1996), who investigated chromosome alterations in car painters from the city of Brasilia, discovering a significant increase in chromosome and/or cromatid anomalies (96\%) in the risk group, as compared to the control group (55\%). They found a deletion rate of $60 \%$ in the painters, and of $20 \%$ in the controls, a proportion similar to the one found in this work. Car painters are exposed to the action of a great number of chemicals, such as solvents whose basis is ketone, aliphatic and aromatic compounds, and esthers, organic and inorganic pigments, and several types of resins whose basis is urethane, multiesthers, multiaculate, isocyanate, besides thinner, which contains benzene. The increased number of MNC found in this work is probably due to the synergistic effect of these products.

The results found in the storage battery renovation workers' group, and the fact that these workers are in contact mainly with lead, a recognized genotoxic agent that causes chromosome breaks, justify the significant increase in the MNC frequency found in this work (Table II). Maluf and Erdtmann (2000) found different results in individuals from a hospital, who had been occupationally exposed to lead, due to activities that involved painting and printing. In the exposed group, there was an average of 16.27 MNC in 2000 lymphocytes, and in the control group an average of 16.0 MNC, no significant increase having been detected . This fact may be due to different levels of exposure between the individuals of this report and the battery renovation workers.

Santos-Mello and Cavalcante (1992) performed a cytogenetic evaluation in gas station workers in the cities of São Paulo and Rio de Janeiro, and found a significant increase in the frequency of chromosome deletions in the metaphases of the exposed individuals $(0.829 \%)$, as compared to controls $(0.126 \%)$. This result is in conformity with the micronuclei frequency findings in our group of car mechanics. Just like the mechanics, gas station workers are

Table IV - Average numbers of micronucleated cells (in 3000 cells analyzed per individual) of the group of individuals exposed to byproducts of petrol and lead, and of controls, with and without drinking habit.

\begin{tabular}{lccccc}
\hline Sample & & \multicolumn{4}{c}{ Micronucleated cells } \\
\cline { 3 - 6 } Individuals & $\mathrm{n}$. & Average & $\begin{array}{c}\text { Standard de- } \\
\text { viation }\end{array}$ & $\begin{array}{c}\text { Minimum } \\
\text { number }\end{array}$ & $\begin{array}{c}\text { Maximum } \\
\text { number }\end{array}$ \\
\hline $\begin{array}{l}\text { Exposed: } \\
\quad \text { With drinking habit }\end{array}$ & 45 & 8.55 & 4.68 & 3 & 25 \\
Without drinking habit & 15 & 7.20 & 2.95 & 3 & 14 \\
$\begin{array}{l}\text { Controls: } \\
\text { With drinking habit }\end{array}$ & 65 & 2.21 & 1.64 & 0 & 6 \\
Without drinking habit & 15 & 2.20 & 1.56 & 0 & 5 \\
\hline
\end{tabular}




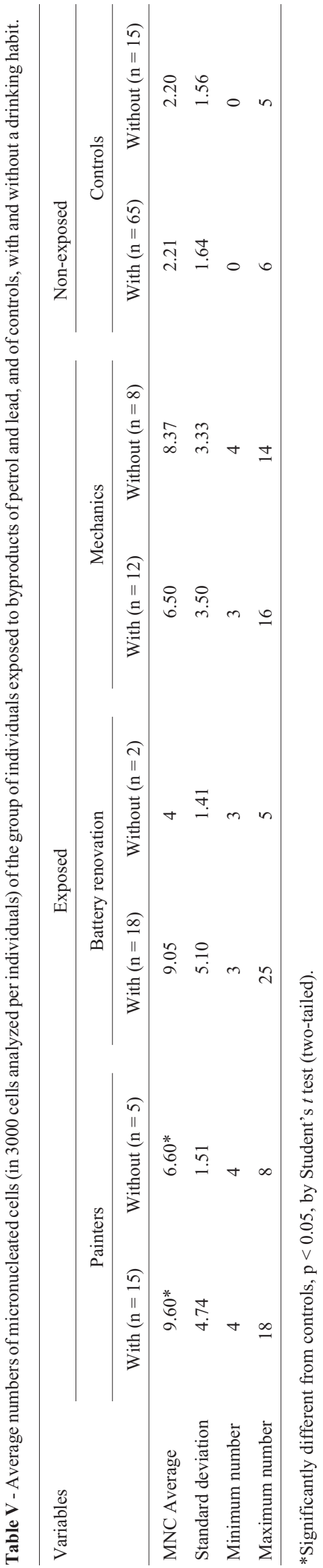

Table VI - Average numbers of micronucleated cells (in 3000 cells analyzed per individual) of the group of individuals exposed to byproducts of petrol and lead, with regard to smoking and drinking habits.

\begin{tabular}{lcc}
\hline Exposed & Without drinking habit & With drinking habit \\
\hline Non-smokers & $8.11 \pm 3.33 \mathrm{MNC}$ & $9.39^{* *} \pm 4.87 \mathrm{MNC}$ \\
& $\mathrm{n}=9$ & $\mathrm{n}=28$ \\
& $3-14 \mathrm{MNC}$ & $4-25 \mathrm{MNC}$ \\
Smokers & $5.80^{* *} \pm 1.72 \mathrm{MNC}$ & $7.17 \pm 4.10 \mathrm{MNC}$ \\
& $\mathrm{n}=6$ & $\mathrm{n}=17$ \\
& $4-8 \mathrm{MNC}$ & $3-18 \mathrm{MNC}$ \\
\hline
\end{tabular}

**Significantly different, when compared, $\mathrm{p}<0.01$, by Student's $t$ test (two-tailed).

exposed to vapors emitted by the ignition of refueling cars, and by the refueling process itself. Among mechanics, the habit of using petrol to clean their hands during car or engine repair is common; therefore, both mechanics and gas station workers inhale petrol gases which contain genotoxic substances, such as benzene and the products derived from engine ignition. These products, when they enter the blood circulation, also present cytotoxic and genotoxic properties, as demonstrated by Hadnagy and Seemayer (1988).

Karahalil et al. (1998) evaluated workers of oil and petrol engine repair garages, using the sister chromatid exchange (SCE) test, and the presence of micronuclei in peripheral blood lymphocytes. The exposed group presented an average of $1.87 \mathrm{MNC}$, and the control group an average of $1.56 \mathrm{MNC}$, which is a significant difference at the $p<0.05$ level. The results of both tests were in agreement with each other. They also agree with the data obtained in this work, which, in fact, were higher in the exposed group than in the controls: $2.85 \mathrm{MNC}$ in the battery renovation workers, $2.95 \mathrm{MNC}$ in the painters, $2.42 \mathrm{MNC}$ in the mechanics, $2.79 \mathrm{MNC}$ in the total of exposed individuals, and $0.74 \mathrm{MNC}$ in the controls.

We also observed that the three evaluated subgroups presented similar results, demonstrating that the agents to which they were exposed, apart from being genotoxic, seem to act with the same intensity. On the other hand a great variation was detected in the individual results of each exposed group, unlike the control group, where the individual data were homogeneous. The MNC frequency variation observed within the exposed groups, characterized by the high values of the standard deviation, must be due to the fact that the response to a given genotoxic agent is different from person to person. This differential response may be the result of different factors, such as genetic constitution and life habits, like drinking, smoking, diet, as well as the adoption of protection measures during exposure, such as mask use. In addition to the standard deviation, the range of variation between the minimum and maximum values of the samples also reflects this variability, which goes from 0 to $6 \mathrm{MNC}$ in the control group, and from 3 to $25 \mathrm{MNC}$ in the exposed group. The variation found among the exposed in- 
dividuals was higher in the battery renovation workers (22 $\mathrm{MNC})$ than in the painters (14 MNC) or in the mechanics (13 MNC), as compared to only $6 \mathrm{MNC}$ in the controls.

According to Dittberner et al. (1997), in in vivo studies about micronuclei induction, like those performed on exfoliated buccal mucosa cells, wide variations are frequent, and the MN frequency is considered a simple and trustful indicator of genotoxic damage in human tissues exposed to carcinogens.

The smoking habit is widely accepted as a major cause of bladder cancer, since $50 \%$ of the cases were identified in smoking men and $1 / 3$ in smoking women (Silverman et al., 1992). However, when analyzing the frequency of MN in the group studied by us, no significant difference was found between the groups of smokers and of non-smokers. There was some difference only between the exposed and the control groups. Maluf and Erdtmann (2000) found no differences either in the number of MNC in cultivated lymphocytes between smokers (13.88 MNC) and non-smokers (16.68 MNC). Similar results found by Karahalil et al. (1998) showed that the smoking habit did not significantly influence the frequency of MNC in cultivated lymphocytes of exposed individuals (1.93 MNC in smokers, and 1.84 MNC in non-smokers) and of controls (1.48 MNC in smokers, and 1.60 MNC in non-smokers). Fonthan et al. (1986) (apud Burgaz et al., 1995), when analyzing exfoliated buccal mucosa cells, detected a 6-fold increase in the number of MNC in smokers. Reali et al. (1987) (apud Burgaz et al., 1995) also reported an increase in the number of MN, after analyzing exfoliated buccal mucosa cells of smokers. Burgaz et al. (1995) found a significant increase in micronucleated cells $(\mathrm{p}<0.001)$ in smokers, as compared to non-smokers.

No significant differences among smokers and non-smokers with regard to MNC were found in this work, either in the exposed or in the non-exposed workers. However, a small decrease in the frequency of MNC was observed in smokers, as compared to non-smokers. Similar results, showing a small increase of micronuclei in the group of exposed non-smokers, were found in studies such as those of Bolognesi et al. (1993), Forni (1994), and Calvert et al. (1998).

Alcoholic beverages have been described as containing mutagenic substances (Maluf and Erdtmann, 2000). Bishop et al. (1997) mention that alcohol does not induce mutations in mammal cells in vitro, whereas in vivo it induces a variety of genetic effects, including sister chromatid exchange and the production of micronuclei, where the evidence, however, is limited to certain test systems or tested organisms. According to Dittberner et al. (1997), alcohol use can increase the number of micronuclei. In the present work, no significant increase in the frequency of $\mathrm{MNC}$ in individuals with a drinking habit was detected, neither in the exposed group, nor in the control group. A significant increase in the number of cells with micronuclei was found in car painters with a drinking habit $(\mathrm{p}<0.05)$, and in storage battery renovation workers $(\mathrm{p}<0.01)$. No differences were detected in the mechanics and control groups.

In the two groups where a significant increase in the number of micronuclei was detected, a higher standard deviation was also observed, approximately 3.5 times the value of those who did not use to drink alcohol. This fact indicates a wide variation in the results, which is due to a differential individual response to the effect of alcohol and to the work exposure.

Although the difference in the frequency of MNC between exposed workers with and without a drinking habit was not significant, an increase in this frequency was observed that may indicate the existence of an influence of alcohol use on the micronuclei formation of exposed individuals, reinforced by the fact that this was not observed in the controls. Therefore, further studies on larger samples or specifically targeted to alcohol use are suggested.

When the interaction between smoking and drinking habits was evaluated, a significant difference was found only between smokers/without a drinking habit and nonsmokers/with a drinking habit. The first ones presented a lower MNC average in relation to the other interactions. These results reinforce those found in the MNC analysis of smokers and non-smokers/with and without a drinking habit. A decrease in the frequency of MNC was verified in the smokers, while in individuals with a drinking habit the frequency of MNC was increased. These results suggest that alcohol, but not smoking, may act synergistically with the substances to which the workers under study were exposed.

Stich and Rosin (1983) evaluated smoking and alcohol consumption over MNC frequency, in order to detect the synergistic effect of these habits. They verified that smokers who drank alcohol presented a significantly increased frequency of MNC in relation to the other interactions. However, no differences were detected in the individual valuation of smoking and alcohol consumption.

Some studies show a positive association between age and MNC frequency, because of the significant increase of modified chromosomes, either in males or females, which happens together with the increase in age (Fenech and Morley, 1989; Nath et al., 1995; Calvert et al., 1998). This work assessed the frequency of MNC in different age groups, not finding any significant differences in the control group. In the exposed group, there was a significant decrease $(p<0.001)$ in the frequency of MNC in the age group of 31 to 40 years, as compared to the 15 to 30 years group. Calvert et al. (1998) and Santos-Mello and Silva (1996) did not find any positive association as to age in their results.

The analysis of MNC frequency after different working times showed a decrease, in both the exposed and the control groups, only after the longest working time (from 
26 to 36 years). Santos-Mello and Silva's (1996) results are in conformity with those of this study, since they found a value of $p=0.48$ for the correlation between working time and chromosome deletions, where the correlation between working time and hypo- and hyperdiploid cells was significant, with $\mathrm{p}=0.0392$. The differences in MNC frequency according to age or time of activity, found in the present study, may be considered random.

\section{Conclusions}

The results make it clear that the mechanics', storage battery renovation workers' and painters' groups presented an increased frequency of cells with micronuclei, due to the genotoxic action of substances to which they were exposed at work. This MNC increase did not show any relation with the smoking and drinking habits, age or working time.

Extensive studies and standardized tests to evaluate biological damage at different levels are recommended to public agencies concerned with environmental quality and public health. Genotoxic evaluation is one of the necessary levels to ensure environmental quality and occupational health, as is the workers' orientation aimed at decreasing genetic damage and risk for serious diseases.

\section{Acknowledgements}

The authors thank the Departamento de Zoologia e Genética do Instituto de Biologia, the Centro de Biotecnologia da UFPel and the technical assistants Álvaro Moreira Martins and Vilma Ruas da Silva, and the 140 workers who spontaneously took part in this study. This research was supported by the Universidade Federal de Pelotas.

\section{References}

Au WW (1991) Cytogenetic assays in monitoring human exposure and prediction of risk. Environmental Mutagenesis Carcinogenesis Teratogenesis 23:236-245.

Bishop JB, Witt KL and Sloane RA (1997) Genetic toxicities of human teratogens. Mutat Res 396:9-43.

Bolognesi C, Parrini M, Merlo F and Bonassi S (1993) Frequency of micronuclei in lymphocytes from a group of floriculturists exposed to pesticides. J Toxicol Environ Health 40:405-411.

Broschinski L, Madle S and Hensel C (1998) Genotoxicity tests for new chemicals in Germany: routine in vitro test systems. Mutat Res 418:121-129.

Burgaz S, Iscan A, Büyükbingöl ZK, Bozkurt A and Karakaya AE (1995) Evaluation of micronuclei in exfoliated urothelial cells and urinary thioether excretion of smokers. Mutat Res 335:163-169.

Calvert GM, Talaska G and Mueller CA (1998) Genotoxicity in workers exposed to methyl bromide. Mut Res 417:115-128.

Carrano AV (1988) Considerations for population monitoring using cytogenetic techniques. Mut Res 204:379-406.
ICPEMC-International Commission for Protection Against Environmental Mutagens And Carcinogens. Publication n. 14.

Dittberner U, Schmetzer B, Gölzer P, Eisenbrand G and Zankl H (1997) Genotoxic effects of 2-trans-hexenal in human buccal mucosa cells in vivo. Mut Res 390:161-165.

Fenech M and Morley AA (1989) Kinetochore detection in micronuclei: an alternative method for measuring chromosome loss. Mutagenesis 4:98-104.

Forni A (1994) Comparison of chromosome aberrations and micronuclei in testing genotoxicity in humans. Toxicol Let 72:185-190.

Hadnagy W and Seemayer NH (1988) Cytotoxic and genotoxic effects of extract of particulate emission from a gasolinepowered engine. Environ Mol Mutagen 12:385-396.

Hirvonen A (1995) Genetic factors in individual responses to environmental exposures. J Occupat Environ Med 1:37-43.

Karahalil B, Burgaz S, Fisek G and Karakaya AE (1998) Biological monitoring of young workers exposed to polycyclic aromatic hydrocarbons in engine repair workshops. Mut Res 412:261-269.

Keshava C, Keshava N, Ong T and Nath J (1998) Protective effect of vanillin on radiation-induced micronuclei and chromosomal aberration in V79 cells. Mut Res 397:149-159.

Kliesch U and Adler ID (1980) Sensitivity comparison of chromosome analysis and micronucleus test in mouse bone marrow. Mut Res 74:160.

Majer BJ, Laky B, Knasmüller S and Kassie F (2001) Use of the micronucleus assay with exfoliated epithelial cells as a biomarker for monitoring individuals at elevated risk of genetic damage and in chemoprevention trials. Mut Res 489:147172.

Maluf SW and Erdtmann B (2000) Evaluation of occupational risk in a Brazilian hospital. Genet Mol Biol 23:485-488.

Nath J, Tucker JD and Hando JC (1995) Y chromosome aneuploidy, micronuclei, kinetochores and aging in men. Chromosoma 103:725-731.

Picker JD and Fox DP (1986) Do curried foods produce micronuclei in buccal epithelial cells? Mut Res 171:185-188.

Santos-Mello R and Cavalcante B (1992) Cytogenetics studies on gas station attendants. Mut Res 280:285-290.

Santos-Mello R and Silva JMGC (1996) Chromosomal aberrations in lymphocytes from car painters. Mut Res 368:21-26.

Silverman DT, Hartge P, Morrison AS and Devesa SS (1992) Epidemiology of bladder cancer. Hemat Oncol Clin 6:1-24.

Stich HF and Rosin MP (1983) Micronuclei in exfoliated human cells as a tool for studies in cancer risk and cancer intervention. Cancer Let 22:241-253.

Titenko-Holland N, Jacob RA, Shang N, Balaraman A and Smith MT (1998) Micronuclei in lymphocytes and exfoliated buccal cells of postmenopausal women with dietary changes in folate. Mut Res 417:101-114.

Titenko-Holland N, Moore LE and Smith MT (1994) Measurement and characterization of micronuclei in exfoliated human cells by fluorescence in situ hybridization with a centromeric probe. Mut Res 312:39-50.

Tolbert PE, Shy CM and Allen JW (1992) Micronuclei and other nuclear anomalies in buccal smears: methods development. Mut Res 271:69-77. 